\title{
ENSINO DE HISTÓRIA, REFORMAS DO ENSINO E PERCEPÇÕES DA ANTIGUIDADE: APONTAMENTOS A PARTIR DA ATUAL CONJUNTURA BRASILEIRA
}

Priscilla Gontijo Leite ${ }^{1}$

RESUMO: O artigo tem como principal objetivo refletir sobre o ensino da História Antiga, bem como sobre a divulgação e a percepção desse conhecimento na sociedade brasileira, principalmente na esfera política. Para tanto, nosso ponto de partida será a conjuntura brasileira que perpassa por um modelo de reforma no ensino que irá impactar diretamente o ensino a respeito da Antiguidade na Educação Básica. Iremos demonstrar a importância do ensino de História Antiga no processo educativo e suas potencialidades para o exercício de uma educação que priorize os valores ligados a autonomia do sujeito e a cidadania.

PALAVRAS CHAVES: Ensino; História Antiga; BNCC; Reforma do Ensino Médio; Política

ABSTRACT: This article aims at reflecting on the teaching of Ancient History and on the dissemination and the perception of this knowledge in Brazilian society, especially in the political sphere. In order to do so, we will start by analyzing current Brazilian political conjuncture in which the educational reform's model will directly impact the teaching about Antiquity in Basic Education. We will demonstrate the importance of teaching Ancient History for educational purposes and its potential for the practice of a type of education that prioritizes values linked to citizenship and individual autonomy.

KEYWORDS: Teaching; Ancient History; BNCC; High School Reform; Politics

Reformulações do ensino brasileiro sempre são temas de acirradas discussões e em 2017 ganham um novo contorno com a sanção da Medida Provisória (MP) $n^{0} 746$ pelo então presidente Michel Temer em 16 de fevereiro. O primeiro ponto de discussão é o mecanismo adotado pelo governo para a implementação da reforma do Ensino Médio, utilizando o instrumento da MP, rompendo com o ciclo de debates que se intensificou em 2015 com as discussões em torno da BNCC (Base Nacional Curricular Comum), ainda não aprovada. O que torna tudo ainda mais peculiar no processo é que o texto da Reforma do Ensino Médio remete diretamente à BNCC, uma vez que 60\% dos conteúdos obrigatórios serão oriundos da Base. Dessa maneira, nota-se que o texto da reforma está mais preocupado como funcionamento do Ensino Médio e,

\footnotetext{
${ }^{1}$ Departamento de História/UFPB
} 
principalmente, de onde virá o dinheiro para custeá-lo, do que propriamente a respeito dos conteúdos ensinados para os jovens.

A implementação da MP se dá mesmo após uma série de protestos protagonizado por estudantes do Ensino Médio no final de 2016, que ocuparam escolas em todo o país. Suas principais reivindicações consistiam na melhoria da educação pública, oposição à condução da reforma do Ensino Médio pelos órgãos governamentais e a solicitação de um maior diálogo com os governos, principalmente na esfera estadual. Apesar das manifestações, a reforma do Ensino Médio continuou a tramitar sob forma de MP no governo federal.

Ainda em 2016, antes da onda de protestos estudantis, a segunda versão da BNCC é lançada. Contudo, esta não foi tão discutida e criticada quanto a primeira, divulgada para consulta popular em 2015. A segunda versão da BNCC ainda possui falhas, e o esvaziamento das discussões em torno dela só pode ser entendida a partir de seu contexto político. O primeiro motivo para o esvaziamento foi o processo de impeachment de Dilma Rousseff, que concentrou a atenção de especialistas das mais variadas áreas, inclusive no campo da educação, e, o segundo, se deu pelo pouco incentivo governamental para fomentar as discussões, alterando, por exemplo, o calendário de discussões até então proposto. Há certo receio de que a BNCC não seja aprovada, ou, então, de que uma versão sem nenhuma discussão prévia passe pelo Congresso.

As discussões em torno da BNCC começaram em 2015, na tentativa de cumprir o PNE de 2014, que determinou o prazo de dois anos para a formulação de uma base curricular para todo o Brasil. Na primeira versão, ficou definido que 60\% dos conteúdos ensinados na Educação Básica deveriam ser provenientes da BNCC, e que os outros $40 \%$ ficariam sob a responsabilidade de estados e municípios, com o objetivo de contemplar toda a pluralidade brasileira. O prazo para a consulta popular terminou em março de 2016, e a mesma foi realizada principalmente por meio eletrônico, através do preenchimento de um formulário, recebendo mais de doze milhões de contribuições, algo inédito no cenário brasileiro. ${ }^{2}$ Porém, esse alto número não significa uma efetiva contribuição. Uma das principais críticas foi o caráter restritivo do formulário e a incerteza no

${ }^{2}$ Cf. Disponível em http://basenacionalcomum.mec.gov.br/\#/site/contribuicao-dados. Acesso em: 28 fev. 2017. 
processamento de todos os dados coletados, principalmente nos campos em que o cidadão poderia escrever sua opinião.

A primeira versão da BNCC recebeu críticas contundentes, e uma das áreas que apresentou o maior número de problemas foi História, a última a ser divulgada. Nesta versão, na descrição dos componentes da História, o exercício da cidadania é utilizado na construção da justificativa da disciplina, bem como aspectos relacionados à pluralidade e ao respeito. A constituição é evocada, com destaque para os benefícios da História para a construção da sociedade democrática brasileira:

O estudo da História contribui para os processos formativos de crianças, jovens e adultos inseridos na Educação Básica, considerando suas vivências e os diversos significados do viver em sociedade. Desse modo, favorece o exercício da cidadania, na medida em que estimula e promove o respeito às singularidades e às pluralidades étnico-raciais e culturais, à liberdade de pensamento e ação e às diferenças de credo e ideologia, como requer, constitucionalmente, a construção da sociedade democrática brasileira. (BNCC, 2015, p. 241, grifos nossos)

A respeito do componente de História, a primeira versão recebeu inúmeras críticas ${ }^{3}$, e uma síntese dos principais pontos está no documento elaborado pela ANPUH-Nacional intitulado Manifestação Pública da ANPUH sobre a Base Nacional Comum, disponível no site da associação4. Dentre as principais críticas, está a predominância de uma história nacional, sem as devidas interlocuções com os outros espaços e tempos; uma crítica má formulada do eurocentrismo; uma tendência a uma formação cívica, pautada apenas nos símbolos nacionais, e não o ensino de uma cidadania crítica e atuante; e, por fim, o objeto de nosso interesse, a forma precária como os conteúdos relativos à História Antiga e História Medieval foram tratados. A única presença da Antiguidade está relacionada a um ensino de uma percepção temporal tratada no

\footnotetext{
3 Para um exemplo vide a posição do professor Pedro Paulo Funari, divulgada no Jornal Folha de São Paulo (23/11/2015), disponível em:

http://www1.folha.uol.com.br/paineldoleitor/2015/11/1709642-mudancas-no-ensino-dehistoria-sao-prejudiciais-diz-professor-da-unicamp.shtml. Acesso em: 24 fev. 2017.

4 Disponível em http://site.anpuh.org/index.php/2015-01-20-00-01-55/noticias2/noticiasdestaque/ item/ 3352-manifestacao-publica-da-anpuh-sobre-a-base-nacional-comumcurricular. Acesso em: 21 abr. 2016.
} 
início do Ensino Fundamental nos itens CHHI6FoA665, CHHI6FoA716, CHHI6FoA727. Dessa maneira, a História Antiga e Medieval praticamente não existe na BNCC e seu ensino ficaria majoritariamente relegado aos $40 \%$ de conteúdos opcionais, a ser definido localmente.

Após a divulgação da primeira versão da $\mathrm{BCNN}$ vários documentos de manifesto produzidos por universidades, associações e instituições foram divulgados, e alguns encaminhados para o MEC. Destacaremos três deles: Carta aberta dos professores do Norte e Nordeste sobre a $\mathrm{BNCC}^{8}$, Carta de repúdio à BNCC produzida pelo Fórum dos profissionais de História Antiga e Medieval9 e Um manifesto pela História e pelas experiências das culturas da Antiguidade ${ }^{10}$. Em comum na justificativa da defesa da História Antiga e Medieval, todos ressaltam a importância da alteridade no ensino de História e como a Antiguidade e o Medievo podem ser utilizados para esse fim:

Destaca-se, outrossim, a importância do exercício da alteridade histórica, elementar a este componente curricular, uma vez que nos permite compreender a formação e a dinâmica de sociedades diferentes da nossa a partir de suas próprias categorias de pensamento, visões de mundo e expectativas sobre a vida bem como modos de agir e pensar, crenças e percepções de si e do outro particulares, já que construídas no tempo (Carta aberta dos professores do Norte e Nordeste sobre a BNCC).

Uma formação plural deve envolver elementos mais heterogêneos, que superem os limites das identidades nacionais e envolvam diversas questões sensíveis aos estudantes. Se, por princípio, as identidades são relacionais, a ausência de variáveis que permitam o contato com as alteridades empobrece de modo significativo a formação humanista dos

\footnotetext{
5 Conhecer e reconhecer diversas maneiras de contagem e de registro do tempo - calendários e outras formas consagradas-, dos astecas, dos maias, dos egípcios, dos diferentes povos indígenas brasileiros entre outros, discutindo usos e adequações. (Brasil, 2015, p. 251)

${ }^{6}$ Conhecer e problematizar as diferentes formas de periodização dos processos históricos tais como o modelo quadripartite francês (Idade Antiga, Idade Média, Idade Moderna e Idade Contemporânea), identificado como o Brasil se insere nesta periodização. (Brasil, 2015, p. 251)

7 Identificar e discutir características, pessoas, instituições, ideias e acontecimentos relativos a cada um desses períodos históricos: Idade Antiga, Idade Média, Idade Moderna e Idade Contemporânea. (Brasil, 2015, p. 251)

${ }^{8}$ Disponível em http://site.anpuh.org/index.php/bncc-historia/item/3149-carta-deprofessores-do-norte-e-nordeste-sobre-a-bncc. Acesso em: 24 fev. 2017.

9 Disponível em http://site.anpuh.org/index.php/bncc-historia/item/3127-carta-de-repudio-abncc-produzida-pelo-forum-dos-profissionais-de-historia-antiga-e-medieval Acesso em: 24 fev. 2017.

${ }^{10}$ Disponível em http://site.anpuh.org/index.php/bncc-historia/item/3123-manifesto-do-gthasobre-a-bncc Acesso em: 24 fev. 2017.
} 
estudantes (Carta de repúdio à BNCC produzida pelo Fórum dos profissionais de História Antiga e Medieval).

O (a) jovem brasileiro(a) tem o direito de possuir uma formação pautada pelo exercício do reconhecimento das diversas experiências/alteridades. Acima de tudo, os jovens brasileiros têm o direito de compartilhar do conhecimento produzido pela humanidade, nem que seja ao menos dos grandes marcos da história mundial a fim de compreender e criticar o mundo em que se inserem, o mundo em que vivem (Um manifesto pela História e pelas experiências das culturas da Antiguidade).

O ensino de História Antiga pautado no exercício da alteridade já é tratado por especialistas da área há quase uma década. Gonçalves e Silva (2008, p. 29-30) e Silva e Gonçalves (2015, p. 7), ao analisarem o ensino de História Antiga nos livros didáticos, demonstram o potencial uso da Antiguidade para o ensino da pluralidade cultural e alteridade, aspecto que, de acordo com eles, não é abordado nos livros didáticos. Os livros didáticos ainda possuem problemas no tratamento da Antiguidade, podendo contribuir para a construção de preconceitos, já que continuam adotando uma visão da Antiguidade eurocêntrica, com simplificações, generalizações, erros graves, anacronismos, juízo de valores e, normalmente, estão desatualizados, utilizando uma linha de raciocínio da primeira metade do século passado. ${ }^{11}$

Considerando esses aspectos, constata-se o distanciamento da primeira versão das recentes pesquisas acadêmicas e dos esforços realizados por professores universitários para a difusão do História Antiga na Educação Básica. ${ }^{12}$ Dessa maneira, a História Antiga permite ao aluno o encontro com o outro, exercitando sua alteridade, permitindo o desenvolvimento da consciência do seu passado e de suas ligações com o presente.

\footnotetext{
${ }^{11}$ Cf. Funari (2004), Gonçalves e Silva (2008, p. 25-28); Rodrigues (2012, p. 26-30); Silva (2010, p. 141), Silva e Gonçalves (2015, p. 9).

${ }_{12}$ Algumas experiências voltadas para o ensino de História Antiga na Educação Básica são: i) PET da UFPR que trata de Pompeia (https://pethistoriaufpr.wordpress.com/); ii) o projeto Aprendendo com Clio - Educação Patrimonial e Cultural Material da Antiguidade conduzido pela UFRJ (http://aprendendocomclio.wix.com/lhia); iii) projeto PROLICEN Vocabulário político da Antiguidade: reflexões para o exercício da cidadania realizado na UFPB e dedicado a produção de material didático e divulgação do conhecimento a respeito da Antiguidade numa perspectiva interdisciplinar; iv) PIBID da FURB, que incentivou o contato dos alunos do Ensino Fundamental com a fonte no original, em grego; v) material educativo desenvolvido pelo LABECA (http://labeca.mae.usp.br/pt-br/professores/).
} 
As ligações entre a Antiguidade e o Brasil, destacando a presença desta no mundo atual, também foi um argumento em comum nos três documentos. A Carta aberta dos professores do Norte e Nordeste sobre a BNCC destaca o fato das experiências da Antiguidade ultrapassarem os limites geográficos, deixando marcas em todo o Mundo Ocidental, como, por exemplo, as línguas latinas, em particular o português, o cristianismo e a democracia. A História Antiga é essencial para entendermos o processo de construção da identidade brasileira como pertencentes ao Ocidente, uma vez que as identidades são socialmente construídas (Guarinello, 2013, p. 8). Assim, nós nos vemos com ocidentais, e a presença da Antiguidade está em diversos aspectos do nosso cotidiano, como explicita Guarinello (2013, p. 13):

Vemo-nos como ocidentais e os textos bíblicos, o Egito, a Mesopotâmia, a Grécia e Roma parecem-nos mais próximos que as Histórias de outros povos e regiões. Não é uma visão falsa em si mesma: falamos uma língua latina, nossa cultura escrita deve muito aos clássicos gregos e latinos, nossas leis e nossa democracia inspiram-se também em textos desse mundo “antigo", e o cristianismo, que nasceu no Império Romano, é nossa religião dominante.

Para além de ressaltar a herança imediata da Antiguidade no Brasil, o documento Um manifesto pela História e pelas experiências das culturas da Antiguidade também destaca acontecimentos contemporâneos que só podem ser plenamente compreendidos a partir do conhecimento do Antiguidade e do Medievo, em particular os atuais discursos políticos, posição da qual concordamos:

Ao contrário do que concebem os idealizadores do currículo de História da BNCC, a História Antiga e também a Medieval não estão tão distantes dele. Como podem os jovens brasileiros entender o que representou a entrada dos tanques americanos sobre os vestígios da antiga Babilônia (no atual Iraque) ou mesmo o saque e a destruição do museu do Iraque, se nada sabem a respeito da sociedade da antiga Mesopotâmia? Vale destacar que alguns dos primeiros selos de escrita da humanidade foram roubados durante esse saque. Como podem entender os embates das guerras étnicas da Europa contemporânea sem nenhum conhecimento do Medievo? Como podem entender os usos da Antiguidade e do Medievo nos discursos políticos contemporâneos, se nada 
conhecem desse passado? (Um manifesto pela História e pelas experiências das culturas da Antiguidade, grifos nossos).

Após receber duras críticas uma nova versão da BNCC é lançada em abril de 2016 e inicia uma rodada de discussões nos estados em forma de seminário, integrando principalmente professores da Educação Básica. Depois os seminários avançariam para universidades e demais instituições e associações para a formulação de uma proposta final. No decorrer de 2016, com a mudança de governo, o calendário de discussões é reformulado e mantêm-se apenas os seminários voltados para os profissionais da Educação Básica. Sob o novo governo, há um silêncio com relação a BNCC e não se sabe se a segunda proposta irá ser amplamente discutida como a primeira.

Na área de História, a segunda versão difere-se substancialmente da primeira, começando pela formulação dos conteúdos, principalmente no Ensino Fundamental. Na nova versão, na descrição do componente da disciplina, o ensino de História contribui para o exercício da cidadania, a pluralidade, a alteridade, a construção da identidade e a boa convivência, mas desaparecem as referências à constituição e à sociedade democrática brasileira. Tal ausência diante da atual conjuntura brasileira saltam aos olhos, ainda mais frente às diversas propostas que buscam alterar direitos assegurados na constituição.

O estudo da História contribui para os processos formativos de crianças, adolescentes, jovens e adultos inseridos na Educação Básica ao ampliar suas vivencias e significados sociais com reflexões sobre os nexos históricos que os constituem. Esse estudo favorecera o exercício da cidadania na medida em que, comprometido com o caráter complexo e plural desses nexos, estimule e promova o respeito as singularidades etnico-raciais e culturais, e a liberdade de pensamento, de ação, de credo religioso, e de opções políticas. Em suma, a partir de procedimentos e temas selecionados, o estudo da História deve contribuir para a consciência de si e do outro, de modo que as identidades sociais possam, compreensivamente, se constituir na relação com outras, dadas em diferentes tempos e espaços sociais, e com elas conviver. (Brasil, 2016, p. 155, grifos nossos)

Com a nova versão, insere-se novamente os conteúdos de História Antiga e Medieval, que se concentram nos primeiros anos do Ensino Fundamental II, 
mas ainda é possível detectar greves problemas, como demonstra a Nota sobre a Segunda Versão da BNCC:

Percebemos mudanças significativas, como a reinserção de história Antiga e Medieval. Entretanto, a maneira como esse conteúdo foi inserido nos desperta curiosidade: afinal, por que a referência exclusiva à Antiguidade Clássica? Quanto ao medievo, o currículo proposto favorece a preservação de estereótipos construídos na historiografia do século XIX, que tende a ver este período histórico a partir de um enfoque teocêntrico. Esta concepção é endossada na Base quando concentra o estudo da Idade Média ao estudo da cristandade, deixando de lado o estudo de realidades plurais existentes no Ocidente europeu, como a cultura islâmica. Consideramos mais grave, no entanto, o fato da Base não mencionar o estudo da história medieval peninsular ibérica, essa sim fundamental para o entendimento da formação do período colonial brasileiro. Em ambos os casos sentimos a grande ausência de referências aos processos históricos vivenciados por outros povos e culturas, sobretudo da África e das Américas (Nota sobre a Segunda Versão da BNCC). ${ }^{13}$

Dessa forma, a inserção dos conteúdos relativos à Antiguidade, porém, não assegura sua qualidade no ensino. Além das carências de aspectos importantes no ensino da Antiguidade e do Medievo e de sua inserção estar construída em modelos historiográficos ultrapassados, a distribuição dos conteúdos sobre Antiguidade também é preocupante, pois pode consolidar determinados estereótipos, como a ideia da superioridade da Antiguidade Clássica. $\mathrm{O}$ ensino da Antiguidade está concentrado entre o $5^{\circ}$ ano e $6^{\circ}$ ano do Ensino Fundamental, o que configura a passagem dos anos iniciais para os anos finais, etapas que possuem objetivos bem diferenciados na BNCC. Nos anos iniciais do Ensino Fundamental, o foco é sensibilizar o aluno para a relação entre vida coletiva e memória, partindo da família até a cidade (Brasil, 2016, p. 298). Também está previsto uma "iniciação à História como forma específica de compreensão da experiência humana e de como ela permite articular e comparar diferentes espaços-tempo, em diferentes sociedades e culturas" (Brasil, 2016, p. 298). Já nos anos finais, o objetivo é apresentar conhecimentos relacionados a

${ }^{13}$ Disponível em http://site.anpuh.org/index.php/mais-rj/noticias-rj/item/3586-nota-sobre-asegunda-versao-da-bncc. Acesso em 24 fev. 2017. 
processos históricos de maior complexidade, que basicamente é um desenrolar linear que vai da Grécia Antiga até o século XX, no mundo pós-Guerra Fria:

Nos anos finais do Ensino Fundamental ganha espaço o desenvolvimento dos conhecimentos necessários à lida com processos históricos de progressiva complexidade, exigindo maior capacidade de abstração, a começar pela mobilização do mundo da antiguidade clássica e medieval. A proposta é a de que esse esforço de afastamento do tempo presente seja facilitado pelo estudo da História do Brasil, e que a reflexão sobre o Brasil se faça sempre presente, ora de forma direta, ora indiretamente, integrando recursos de linguagem e procedimentos de pesquisa (Brasil, 2016, p. 46o, grifos nossos).

Dessa forma, a passagem dos anos inicias para os finais do Ensino Fundamental se dá a partir do ensino da Antiguidade, com o desenvolvimento da agricultura e das primeiras cidades, passando para o estudo dos povos da região do Oriente Médio e Egito, com o objetivo do aluno desenvolver o raciocínio histórico:

Por meio da exploração dos primeiros indícios da presença da humanidade na Terra, até as primeiras civilizações, $\mathrm{o} / \mathrm{a}$ estudante vai, concomitantemente, tomando contato com conhecimentos históricos já consolidados e aprendendo a pensar com a História. A articulação entre objetivos de aprendizagem voltados para o conhecimento e objetivos de aprendizagem voltados para o desenvolvimento da linguagem e de procedimentos históricos constituem um processo único e integrado de desenvolvimento do raciocínio histórico, que prepara o/a estudante para a tomada de contato com um quadro mais abrangente a partir do $6^{\circ}$ ano (Brasil, 2016, p. 460).

De acordo com a perspectiva adotada na segunda versão, a complexidade dos processos históricos se inicia com a Antiguidade Clássica. Além disso, fica evidente a utilização da divisão da História Antiga em História Antiga do Oriente Próximo e História Antiga Clássica, com a predileção para a segunda, criando na memória coletiva o enquadramento de que pertencemos à história do Ocidente (Guarinello, 2013, 7-15). Egito e a Mesopotâmia estão no campo do exótico, o que reforça uma tendência eurocentrista que a proposta tenta tanto combater, bem 
como não auxilia na promoção do estudo da alteridade que a proposta tanto almeja.

De acordo com a proposta e a disposição dos conteúdos, a história dos povos do Egito e da Mesopotâmia serve apenas de preparação para a história de outros povos mais complexos, como os gregos e os romanos. A estrutura da proposta demonstra uma evolução progressiva e linear de povos mais simples para povos mais complexos, em que os primeiros estão justamente localizados no Oriente (Egito e Mesopotâmia) e os mais "evoluídos" estão no Ocidente e são os herdeiros da tradição greco-romana, com ênfase ao ensino da democracia grega, do direito romano e da ascensão do cristianismo. Os conteúdos são dispostos de forma linear, devendo o professor proceder segundo esta ordem: o ensino da Mesopotâmia, Egito, Grécia, Roma, ascensão do cristianismo, fim do Império Romano e o surgimento da ordem medieval - como demonstra o conteúdo EFo6HI21: "Classificar a estrutura da sociedade feudal definida a partir de três ordens, dos oratores, bellatores e laboratores, representadas pelas figuras do sacerdote, do cavaleiro e do camponês” (Brasil, 2016, p. 470).

Seguindo a disposição linear da proposta, os estudos sobre a Antiguidade iniciam-se no $5^{\circ}$ ano, quando o aluno tem em média 10 anos de idade, com a Mesopotâmia e Egito. ${ }^{14}$ No $6^{\circ}$ ano, com a idade média de 11 anos, o aluno tem o contato com a história grega, com a ênfase nos aspectos políticos e na história de Atenas. ${ }^{15}$ Segue-se, então, o estudo de Roma, ressaltando também aspectos políticos, como a construção do República, do Império e a questão do Direito, como indica os conteúdos EFo6HIo $7^{16}$ e EFo6HIo8 ${ }^{17}$, além de destacar o papel do cristianismo ${ }^{18}$. A Antiguidade se encerra no $6^{\circ}$ ano com o estudo da passagem do Antiguidade para o Medievo. ${ }^{19}$

\footnotetext{
14 (EFo5HIo8) Conhecer as primeiras civilizações na Ásia e na África (a Mesopotâmia, a Pérsia, o Egito faraônico, os povos núbios e hebreus) (Brasil, 2006, p. 303).

15 (EFo6HIo1) Conhecer a história da Grécia antiga, com ênfase no processo de surgimento da polis e da Filosofia. (EFo6HIo2) Reconhecer os conceitos de democracia e cidadania construídos na Grécia clássica e, em particular, em Atenas (Brasil, 2006, p. 462).

${ }^{16}$ Conhecer o processo de formação do Império Romano (Brasil, 2016, p. 464).

${ }_{17}$ Compreender aspectos da República romana e o papel do Direito na organização do Estado (Brasil, 2016, p. 464).

18 (EFo6HIo14) Identificar as origens do Cristianismo na região da Palestina e sua propagação por outras regiões do Império Romano (Brasil, 2016, p. 466).

19 (EFo6HI17) Compreender a desestruturação do Império Romano e a formação do mundo medieval na Europa (Brasil, 2016, p. 468).
} 
Depois do $6^{\circ}$ ano, não há qualquer menção à Antiguidade nos $7^{\circ}, 8^{\circ}$ e $9^{\circ}$ anos, desaparecendo completamente durante o Ensino Médio, que prioriza o ensino da História do Brasil e da sua relação com o continente americano a partir da época moderna até os dias de hoje. Com relação ao Ensino Médio, a segunda proposta é muito semelhante a primeira, e que deve ser adotada com a implementação da Reforma do Ensino Médio.

Com esta disposição dos conteúdos, durante toda a Educação Básica, o aluno terá contato com a história dos povos da Antiguidade na faixa etária média entre 10 e 12 anos, momento em que ainda está em formação seu raciocínio histórico. Ele, assim, terá dificuldades de perceber as complexidades de cada um dos povos antigos, podendo formar vários preconceitos, como vem acontecendo no ensino da Antiguidade na Educação Básica atualmente. ${ }^{20}$

Outro ponto problemático na BNCC é a não retomada dos conteúdos da Antiguidade nas séries seguintes, nem mesmo na abordagem sobre 0 Renascimento, que é o primeiro conteúdo do $7^{\circ}$ ano do fundamental (EFo7HIo1). Sem os estudos sobre a recepção e a reapropriação da Antiguidade, o aluno irá sair da Educação Básica sem conseguir perceber que a Antiguidade esteve sempre presente no horizonte político e cultural do Ocidente.

A forma como a Antiguidade é apresentada na BNCC não se difere das críticas apresentadas há tempos por especialistas no que se refere ao ensino da História Antiga na Educação Básica. Hoje, como é evidente nos livros didáticos, tem-se uma divisão temporal tripartida que vai do Oriente (com o destaque para Mesopotâmia e Egito) para o Ocidente (Grécia e Roma). De acordo com Gonçalves e Silva, essa divisão era a mesma presente nos currículos da década de 1960, em que os estudos da Antiguidade se concentravam em torno do conceito de civilização, a fim de entender a trajetória da civilização ocidental, que se iniciaria com o surgimento de civilizações na beira dos rios Tigre e Eufrates até o desenvolvimento das civilizações do Mediterrâneo (Gonçalves e Silva, 2008, p. 25-28). Além disso, os autores ressaltam a predominância de uma visão eurocêntrica sobre a História do Egito, Mesopotâmia, Grécia e Roma, com a valorização dos fatos políticos (Gonçalves e Silva, 2008, p.31), aspecto que também permanece forte na BNCC, que, no que se refere à Antiguidade, parece

${ }^{20}$ Cf. Rodrigues, 2012, 30-32. 
estar mais próximo de modelos de propostas curriculares já ultrapassadas do que da recente produção científica.

Desta forma, a concentração dos conteúdos relacionados à História Antiga no Ensino Fundamental e sua absoluta ausência no Ensino Médio, bem como a proposta de Reforma do Ensino Médio, provocarão um afastamento desses conteúdos na vida dos jovens e, consequentemente, dos cidadãos. Um dos pontos polêmicos da Reforma do Ensino Médio relaciona a formação dos profissionais da educação a partir do notório saber. ${ }^{21}$ Como indicado por Funari (1997, 85-86), no passado, a História Antiga no Brasil carecia de profissionais formados na área, atuando profissionais de outras, que por vezes utilizavam uma bibliografia ultrapassada, o que poderia levar um desinteresse do aluno em aprofundar os estudos. Atualmente, o cenário está mais favorável, com a atuação de profissionais formados na área em todas as regiões do Brasil, como pode ser verificado no site do Grupo de Trabalho de História Antiga da ANPUH-Brasil. ${ }^{22}$ $\mathrm{O}$ avanço dessa área de conhecimento também pode ser atestado pelas revistas acadêmicas especializadas e pela atuação de grupos de pesquisa e laboratórios, muitos com parcerias internacionais. Refletindo a partir da própria trajetória da História Antiga no Brasil, não é possível sustentar a possibilidade de atuação por "notório saber" beneficiar o cenário da educação brasileira, gerando uma precarização do ensino e das condições de trabalho do professor, em especial daqueles que buscam uma formação continuada em programas de pósgraduação.

A Reforma do Ensino Médio também não especifica como se dará a formação dos itinerários formativos e abre a possibilidade da inserção da modalidade de ensino à distância online $(\mathrm{EaD})$, conforme indica o parágrafo $4 .{ }^{23}$ Por isso, não há qualquer garantia de que a Antiguidade seja estudada no Ensino Médio e pode-se até mesmo ser criado um itinerário formativo da área das Humanidades sem qualquer referência à Antiguidade. Há um sério risco de que

\footnotetext{
${ }^{21}$ Art. $6^{\circ}$ O art. 61 da Lei $n^{\circ}$ 9.394, de 20 de dezembro de 1996, passa a vigorar com as seguintes alterações: VI- profissionais com notório saber reconhecido pelos respectivos sistemas de ensino, para ministrar conteúdo de áreas afins à sua formação ou experiência profissional, atestados por titulação específica ou prática de ensino em unidades educacionais na rede pública ou privada ou das corporações privadas que tenham atuado para atender ao inciso V do caput do art. 36 (Brasil, 2017, p. 5).

$22 \mathrm{http} / / /$ www.gtantiga.com/estados.htm

23 \$11 Para efeito de cumprimento das exigências curriculares do Ensino Médio, os sistemas de ensino poderão reconhecer competências e firmar convênios com instituições de educação a distância com notório reconhecimento (Brasil, 2017, p. 4).
} 
todo o conhecimento produzido pelas universidades brasileiras neste campo do saber não consiga chegar às salas de aulas da Educação Básica.

Dessa forma, as mudanças na área da educação propostas pela Reforma do Ensino Médio e pela BCNN irão impossibilitar ao aluno um conhecimento pleno e crítico da Antiguidade, prejudicando sua formação e capacidade de entender um mundo que os rodeia. A Antiguidade é essencial para entender o campo político, uma vez que nossas instituições políticas e nosso vocabulário político é majoritariamente herança greco-romana, e os jovens, por sua vez, devem entender suas origens, transformações ao longo do tempo e seu funcionamento para atuarem plenamente nelas. Além disso, muitos discursos políticos utilizam a Antiguidade para legitimar seus argumentos, sendo o uso do passado algo comum na retórica. A título de exemplo sobre os usos do passado nos discursos políticos, demonstraremos a utilização de aspectos relacionados à Antiguidade por deputados federais e senadores durante o processo de impeachment de Dilma Rousseff, evento político de grande envolvimento social e com ampla cobertura midiática.

No dia 11 de abril de 2016, durante a sessão da Comissão Especial para dar o parecer sobre o crime de responsabilidade fiscal em que se baseou o pedido de impeachment, Weliton Prado (PMB-MG), favorável à instauração do processo, inicia seu discurso evocando Ésquilo, pronunciado como "Esquilo":

Em frase atribuída a Ésquilo, dramaturgo grego nascido no ano 525 antes de Cristo, "Na guerra, a primeira vítima é a verdade".

Pois é o que se tem no momento presente vivido no Brasil: população se divide e se combate, lançando mão dos artifícios mais condenáveis, porque uns entendem haver razão para os denunciantes que acusam a Presidente da República de cometer crime de responsabilidade e outros veem tentativa de golpear a democracia representativa com tal denúncia. ${ }^{24}$ (grifos nossos)

Logo depois, no dia 15 de abril de 2016, no discurso de Marcos Soares (DEM-RJ) também favorável ao impeachment, a Grécia é novamente evocada, como sendo a precursora da teoria da divisão de poder. ${ }^{25}$ Nos dois casos, fica

\footnotetext{
24 Disponível em http://www.camara.gov.br/sileg/integras/1449741.pdf. Acesso em 21 abr. 2016. 25 "A usurpação do poder, prerrogativas e funções do Estado não é intervenção nova. Já existia desde a Grécia antiga. Pensou-se por lá na teoria da tripartição dos Poderes do Estado. Mesmo
} 
evidente o desconhecimento a respeito da Antiguidade, seja pela pronuncia errada, seja pela informação equivocada a respeito da pólis, pois a aplicação da teoria da divisão de poderes não é possível, já que as esferas políticas, cívica, religiosa, jurídica e legislativa eram profundamente imbricadas: por exemplo, um cidadão ateniense poderia exercer funções judiciárias e legislativas. Na pólis democrática, era valorizado o processo participativo ativo e direto, com decisões coletivas tomadas depois de deliberação mediada pela palavra. ${ }^{26}$

Dias depois, em 17 de abril de 2016, Conceição Sampaio (PP-AM) utiliza uma citação de Platão para justificar seu voto, enaltecendo o papel do juiz, equiparando sua ação de votar a favor do impeachment com um ato de justiça, de acordo com as leis. ${ }^{27}$ No dia seguinte, Gonzaga Patriota (PSB-PB) com o voto também favorável ao impeachment, fez a equivalência desse procedimento com o ostracismo, informando para a audiência que o afastamento de um presidente remonta aos inícios da República:

Hoje em dia, na maioria dos países onde a democracia representativa e o sistema presidencialista estão em vigência, há a possibilidade de o Presidente da República ser afastado do poder em casos de crimes contra o bem público, previstos em suas cartas constitucionais, por meio de um processo de impeachment. Esse tipo de processo remonta à tradição política inglesa e também às mais antigas civilizações. Um caso clássico é o ostracismo, que ocorria no seio da civilização ateniense, na Grécia Antiga. ${ }^{28}$

Esta fala é sintomática sobre a percepção da Antiguidade no Brasil, principalmente no que se refere à Grécia e Roma, que são vistas como indissociáveis, principalmente no campo político. Não há uma separação entre a prática republicana romana e a democracia ateniense, remetendo o processo de impeachment à Antiguidade, o que é equivocado. O uso retórico do ostracismo

assim, não se conseguia vislumbrar algo tão difícil, ou seja, o respeito às diferenças e às funções administrativas exercidas pelos Poderes.” Disponível em https://goo.gl/5nk6Ry. Aceso em: 20 dez. 2016.

${ }^{26}$ Para mais informações sobre a cultura política da participação direta e o papel do cidadão na democracia ateniense ver Dabdab Trabulsi (2006); Arnason, J. P., Raaflaub, K. A., Wagner, P. (2013).

${ }^{27} \mathrm{Sr}$. Presidente, gostaria, em primeiro lugar, de agradecer a Deus por este momento e pedir-lhe misericórdia para nossa Nação. Não acho que, no final desta noite, teremos vencidos nem vencedores, mas quero lembrar aqui uma frase de Platão: $O$ juiz não é nomeado para fazer favores com a justiça, mas para julgar segundo as leis. Pelo Amazonas, pelo Brasil, o meu voto é sim. Disponível em https://goo.gl/9Dok6b. Acesso em: 21 abr. 2016.

${ }^{28}$ Disponível em https://goo.gl/vvOzBO. Acesso em: 20 dez. 2016. 
não permite espaço para descrever seu funcionamento, pois, dessa forma, todo o argumento seria derrubado. $\mathrm{O}$ ostracismo era uma medida legal em que qualquer cidadão poderia perder seus direitos cívicos, e não apenas aquele que é alvo do processo, como é no caso do impeachment.

No Senado, ainda encontramos mais dois exemplos do uso da Antiguidade. O senador Pedro Chaves (PSC-MS) inicia seu discurso afirmando que os gregos antigos estabeleceram os mecanismos de representação popular, e cabe ao político ter a missão de escolher o que é o mais correto e melhor para o povo, o que no seu argumento, é o impeachment de Dilma Rousseff. Já o senador José Pimentel (PT-CE), para repudiar o impeachment, utiliza a imagem do Império Romano, destacando sua "exploração" aos mais pobres.

A utilização de referências da Antiguidade na Câmara dos deputados e no Senado apresenta algumas diferenças, que são intrínsecas à própria natureza do discurso, já que no Senado o tempo de fala é maior, permitindo a construção de argumentos mais elaborados. Dessa forma, a Antiguidade entra como um dentre outros componentes do passado listado para demonstrar o valor do político na sociedade, ressaltando principalmente sua missão e que suas ações estão em sintonia com a vontade popular. Na Câmara, apesar dos discursos serem menores, a Antiguidade é majoritariamente evocada de forma errada, demonstrando pouco conhecimento sobre o assunto e falta de preparo do discurso. Em comum, o uso da Antiguidade por deputados federais e senadores não corrobora significativamente nenhum ponto da argumentação e poderia ser facilmente omitido do discurso sem prejuízo para o entendimento das ideias. Mas por que razão a insistência em utilizar a referência aos Antigos? Uma hipótese é a de que isso demonstraria certa erudição. O conhecimento da Antiguidade sempre esteve relacionado a domínio de uma erudição ${ }^{29}$ e por muito tempo o acesso a esse conhecimento era restrito a membros da elite.

A pretensa erudição se descontrói com uma educação de qualidade, no qual os conteúdos ensinados sejam significativos e partes integrantes da vida dos cidadãos. A utilização de exemplos do passado por partes dos políticos brasileiros demonstra a importância do estudo de História para a sociedade, pois dependendo da forma como a História é ensinada, colaborará para a continuidade dessa pretensa erudição, principalmente se for ensinada uma 
História enquanto uma narrativa única e verdadeira do passado. O que deve ser ensinado é a História enquanto ciência, capaz de produzir um discurso científico passível de ser discutido igualmente por termos científicos (Guarinello, 2013, p. 11). É a História como ciência que possibilitará uma educação pautada em valores cidadãos, no respeito e na pluralidade, objetivos presentes nos componentes da História nas duas versões da BNCC. Porém quando analisamos a descrição dos conteúdos, principalmente na segunda versão da BNCC, nota-se a predomínio da História enquanto verdade, numa discussão linear e com a apresentação evolucionista dos fatos.

A maneira como está sendo conduzida a Reforma do Ensino Médio e a construção da proposta da BNCC pode limitar o acesso do aluno ao conhecimento histórico científico, prejudicando sua formação. Nota-se que com essas medidas o ensino de História Antiga na Educação Básica será prejudicado, podendo gerar a construção de uma imagem da Antiguidade mais ligada ao campo do mítico do que do real, com a caracterização dos personagens sendo feita principalmente na imagem de deuses e heróis e o conhecimento adquirido através de filmes e outros suportes. Quais os riscos de se ter uma Antiguidade na esfera do fantasioso e utilizada no campo da pretensa erudição? O principal risco é a incapacidade de criticar aspectos importantes da esfera política, como os discursos acima apresentados, além do desconhecimento de elementos básicos relacionados ao vocabulário político atual e a teoria das formas de governo.

Assim, a partir da experiência política recente brasileira, nota-se que a Antiguidade é majoritariamente utilizada para legitimar uma ordem social, um determinado status quo, sob um viés conservador. Tal uso é referendando com a proposta da BNCC e da reforma do Ensino Médio ao apresentar uma Antiguidade pouco crítica, factual e restrita. Diante desse cenário, o principal desafio do especialista em Antiguidade é transformar o ensino deste conteúdo em algo que seja significativo (Funari, 2004, p. 5), presente na vida do aluno, fazendo sentido para as preocupações do agora (Guarinello, 2004, p. 5), e potencializando o exercício da cidadania. É inegável o papel fundamental do ambiente escolar no desenvolvimento de uma consciência crítica, que é essencial para um cidadão atuante e participativo na esfera política.

O Brasil atual precisa da História Antiga e de seu ensino em todos os níveis da educação, para que nos permita encontrar novas leituras de mundo e, 
com esse novo olhar, possamos encarar os desafios futuros, principalmente no campo da política.

\section{Referências Bibliográficas}

Arnason, J. P., Raaflaub, K. A., Wagner, P. (eds). The Greek polis and the invention of democracy: a political-cultural transformation and its interpretation. Oxford, Wiley- Blackweel, 2013.

Brasil. Base Nacional Curricular Comum. Brasília, 2015.

Brasil. Base Nacional Curricular Comum. Brasília, 2016.

Chevitarese, André L.; Cornelli, Gabriele; Silva, Maria Aparecida de Oliveira (orgs.). A tradição clássica e o Brasil. Brasília: Archai-UNB/Fortium, 2008.

Dabdab Trabulsi, José Antônio. Participation directe et démocratie grecque Une histoire exemplaire? Besançon: Presses universitares de Franche- Comté, 2006

Gonçalves, Ana Tereza Marques; Silva, Gilvan Ventura da. O ensino de história antiga nos livros didáticos brasileiros: balanço e perspectivas. In: Chevitarese, André L.; Cornelli, Gabriele; Silva, Maria Aparecida de Oliveira (orgs.). A tradição clássica e o Brasil. Brasília: Archai-UNB/Fortium, 2008.

Funari, P. P. A.; Garraffoni, R. S. História Antiga na sala de aula. Coleção Textos Didáticos, n. 51, 2004.

Funari, P. P. A.; Garraffoni, R. S. Considerações sobre o estudo da Antiguidade Clássica no Brasil. Acta Scientiarum. Education Maringá, v. 32, n. 1,2010, p. 1-6.

Funari, P. P. A. A importância de uma abordagem crítica da História Antiga nos livros escolares. Revista História Hoje, São Paulo, n. 4, 2004. P.1-6.

Funari, P. P. A. Cidadania, erudição e pesquisas sobre a Antiguidade clássica no Brasil. Boletim do CPA, Campinas, $\mathrm{n}^{\circ}$ 3, jan./jun. 1997.

Guarinello, Noberto Luiz. História Antiga. São Paulo: Contexto, 2013.

Leite, Priscilla Gontijo. Ensino de história, conjuntura política brasileira e democracia: reflexões a partir da Antiguidade. Anais do XVII Encontro Estadual de História - ANPUH-PB. v. 17, n. 1, 2016, p. 1312-1322.

Rodrigues, Renata Cardoso Belleboni. Reflexões no ensino da História Antiga. Revista NUPEM. V. 4, n.7, 2012, p. 25-36.

Silva, Semíramis Corsi. Aspectos do Ensino de História Antiga no Brasil: algumas reflexões. Alétheia: Revista de estudos sobre Antigüidade e Medievo, Vol. 1, Janeiro a Julho 2010. p. 145-155.

Silva, Lisiana Lawson Terra da; Gonçalves, Jussemar Weiss. O ensino de História Antiga: algumas reflexões. Anais eletrônicos do XXVIII Simpósio Nacional de História. 2015.

Manifestação Pública da ANPUH sobre a Base Nacional Comum. Disponível em: http://site.anpuh.org/index.php/2015-01-20-00-01-55/noticias2/noticiasdestaque/item/3352-manifestacao-publica-da-anpuh-sobre-a-base-nacionalcomum-curricular. Acesso em 21/04/2016. 